\title{
Clinical Feasibility of Suppression Head Impulse Test in Vestibulopathy Patients
}

\author{
Yun Jin Kang, Beom Cho Jun, Ye Sun Cho, Ji Hyung Lim, and Do Yeon Kim \\ Department of Otorhinolaryngology-Head and Neck Surgery, College of Medicine, The Catholic University of Korea, Seoul, Korea
}

\section{전정 질환 환자에서 억제 두부충동검사의 임상적 유효성}

강윤진 · 전범조 · 조예선 · 임지형 · 김도연

가톨릭대학교 의과대학 이비인후과학교실

Received April 13, 2017

Revised June 23, 2017

Accepted July 12, 2017

Address for correspondence

Beom Cho Jun, MD, PhD

Department of Otorhinolaryngology-

Head and Neck Surgery,

College of Medicine,

The Catholic University of Korea, Uijeongbu St. Mary's Hospital,

271 Cheonbo-ro, Uijeongbu 11765,

Korea

Tel $+82-31-820-3657$

Fax $+82-31-847-0038$

E-mail otojun@gmail.com
Background and Objectives The suppression head impulse (SHIMP) test has emerged as one of the new vestibular function tests. The SHIMP test is an analysis of anti-compensatory saccadic movements in gazing moving targets as the head moves. In this study, we investigated the accuracy and sensitivity of the test.

Subjects and Method We analyzed the results of SHIMP test (gain, amplitude, and latency) in 24 cases, which included normal, vestibular neuritis, benign paroxysmal positional vertigo (BPPV), Meniere's disease, bilateral vestibular function loss, temporal bone fracture, tuberculosis meningitis and acoustic schwannoma patients. We also carried out a physical exam, audiologic study, video electronystagmography (vENG) and a conventional video head impulse test to evaluate the feasibility of SHIMP test in cases of vesitibulopathy.

Results In patients with vestibulopathy, the analysis of SHIMP test indicated high sensitivity and accuracy, which were supported by accompanying audio-vestibular studies. Patients suspected with BPPV, vestibular neuronitis and Meniere's disease showed low vestibulo ocular reflex (VOR) gain and delayed anticompensatory saccade with smaller and more scattered amplitudes than the control. Patients with bilateral vestibular function loss, temporal bone fracture, tuberculosis meningitis, and acoustic schwannoma showed delayed latency, and small amplitude or few anticompensatory saccades. Finally, changes in the SHIMP test values might be a hint that patients had recovered from vestibular neuronitis and tuberculosis meningitis.

Conclusion We found the feasibility of SHIMP test in detecting the pathologic condition of VOR in vestibulopathy patients. We argue that the usefulness of SHIMP test might be extended to evaluating the effectiveness of rehabilitation.

Korean J Otorhinolaryngol-Head Neck Surg 2018;61(2):76-84

Key Words Head impulse test · Saccades · Vestibular function tests ·

Vestibulo-ocular reflex $\cdot$ Vestibulopathy.

\section{서 론 \\ 두부충동검사는 두부의 각 가속 회전운동으로 인한 내림 \\ This is an Open Access article distributed under the terms of the Creative Commons Attribution Non-Commercial License (http://creativecommons.org/licenses/by-nc/4.0) which permits unrestricted non-commercial use, distribution, and reproduction in any medium, provided the original work is properly cited.}

프액의 이동을 각 말단 전정감각기에서 감지하여 외안근의 움직임을 유발하는 전정 안반사를 통해 전정 상태를 파악하 는 검사이다. 이는 시행하기 용이하고, 두부를 다양한 각도로 회전시킴을 통해 양측의 세 가지 세반고리관 팽대부를 모두 자극하여 평가할 수 있다는 장점이 있어 현재 널리 사용되고 있다. $^{1-4)}$ 
억제 두부충동검사(suppression head impulse test)는 두 부충동검사의 일종으로 비디오 두부충동검사(video head impulse test)의 장비에 다른 검사의 패러다임을 적용하여 기존 두부충동검사에서 관찰할 수 없었던 전정 안반사(vestibuleocular reflex)를 억제하는 방향으로의 안구 움직임을 관찰 하여 잔존 전정 기능을 파악하는 검사이다. 이는 머리의 움직 임과 같이 동일한 방향과 각도로 움직이는 타깃에 대한 안구 움직임의 변화를 분석하는 방법으로, 정상 전정 기능을 가진 경우 정상적 전정 안반사가 일어나 머리를 회전한 후에 반보 상적 단속운동이 나타나는 반면, 전정 기능 손상이 있을 경우 전정 안반사가 위축되거나 소실되어 단속운동 없이 이 과정이 완료된다. 그러므로 억제 두부충동검사에서 단속운동은 잔존 전정 기능을 의미한다.

현재까지 억제 두부충동검사의 데이터를 분석, 그 정확도 와 민감도에 대해 기술한 연구는 부족하여 그 유용성에 대 해 보다 폭넓은 대상으로 연구 및 분석이 필요한 상황이다. 따라서 본 연구에서는 전정 기능 이상이 없는 정상인과 양성 돌발성 체위성 현훈, 전정신경염, 메니에르병과 같이 전정 기능 이상으로 인한 현훈을 호소하는 환자들의 억제 두부충동검 사 결과 및 기타 전정검사 결과를 비교하여 검사의 임상적 유용성을 알아보고자 하였다.

\section{대상 및 방법}

2016년 11월부터 2017년 3월까지 의정부성모병원 이비인후 과에 내원하여 비디오 두부충동검사 및 비디오 억제 두부충 동검사를 시행한 정상인 및 현훈을 호소하는 환자 총 24 명을 대상으로 하여, 후향적으로 검사 결과를 분석하였다.

고전적 비디오 두부충동검사에서는 환자에게 90 100 cm 정도 거리를 둔 벽에 고정된 타깃에 시선을 고정하고, 20 50 회 정도 머리를 수평 방향으로 무작위 회전시켜도 해당 초점 에 시선을 고정하고 있도록 교육하였다. 억제 두부충동검사 (ICS impulse ${ }^{\circledR}$, Otometrics, Taastrup, Denmark)에서는 환자 들을 벽에서 $1 \mathrm{~m}$ 정도 거리를 두고 앉게 한 뒤 무작위 방향 으로 머리가 움직이면 초점이 함께 이동함을 교육한 뒤, 해 당 초점에 시선을 고정하도록 설명하고 검사를 시행하였다.

전정 기능의 이상이 없는 정상 $(n=1)$, 전정신경염으로 진단된 환자군(안진검사에서 머리 움직임에 따른 일측성의 명확한 수평 자발 안진과 칼로리검사에서 $25 \%$ 이상의 기능소실이 있 은 경우; n=3, age range 54 74), 양성 돌발성 체위성 현훈으 로 의심된 환자군(dix-hallpike검사 및 칼로리검사에서 두위 변화 시 방향에 따라 명확한 안진이 나타나는 경우; $n=8$, age range 49 60), 메니에르 질환군으로 의심된 환자군(과거 병
력상 재발성 어지럼 동반 및 순음청력검사상 일측 청력 저하가 동반됨을 확인한 경우; $n=8$, age range 47 66), 양측 전정 기 능 저하가 있는 환자(칼로리검사 결과 전체 반응값이 20보다 작은 경우), 어지럼이 동반된 측두골 골절 환자(측두골 컴퓨터 단층촬영영상에서 횡골절이 진단된 경우), 결핵성 수막염 환 자(뇌척수액검사에서 진단된 경우), 전정신경초종 환자(측두 골 컴퓨터단층촬영 및 자기공명영상에서 진단 및 수술 후 조 직검사상에서 진단된 경우)를 대상으로 검사 진행하였다.

억제 두부충동검사 결과를 해석할 때에는 반보상적 단속 운동에 주목하여 전정 안반사의 획득값(gain), 지연값(latency) 과 진폭값(amplitude)을 분석하였다. ${ }^{1,5,6)}$ 획득값은 머리 움직 임 속도 그래프 면적에 대한 눈의 비단속운동 속도 그래프의 면적 비율로 측정하였으며 지연값은 강한 단속운동이 관찰 되는 시점으로 정상적으로는 머리 회전 자극이 시작된 직후 부터 강한 반보상적 단속운동이 관찰되는 시점을 측정하였 다. 진폭값의 경우, 각 단속운동의 속도가 최저 혹은 최고일 때 해당 속도의 절대값들을 합하여 단속운동을 확인한 총 자 극 횟수로 나눈 값으로 정의하였다.

\section{결 과}

\section{정 상}

먼저 전정 기능의 이상이 없는 정상인의 경우, 고전적인 비 디오 두부충동검사 결과 보상적 단속운동이 나타나지 않았으 나, 억제 두부충동검사 결과 전정 안반사를 억제하는 방향으 로 안구 움직임이 나타나는 반보상적 단속운동이 일어남을 확 인할 수 있었다(Fig. 1). 아울러 이는 두부충동이 종료된 이후 에 나타나는 비중복 단속운동(overt anticompensatory saccadic movement)으로 나타남을 확인할 수 있었다. 획득값은 약 1.0 전후로 측정되어 전정 안반사 기능이 정상임을 확인할 수 있었다.

\section{양성 돌발성 체위성 현훈 환자}

양성 돌발성 체위성 현훈 환자군의 억제 두부충동검사 결 과 대조군보다 더 명확하게 구분되는 반보상적 단속운동의 지연이 일어나, 고전적인 두부충동검사에서 머리와 눈의 움 직임의 속도 그래프가 중복되어 나타나 명확하게 구분할 수 없 었던 보상적 단속운동에 비하여 보다 명확하게 전정신경 기 능 저하를 판단할 수 있었다.

좌측 외반고리관의 양성 돌발성 체위성 현훈 환자(Fig. 2)의 경우, 기존 두부충동검사 결과 좌측 수평으로 두부 회전 시 보상적 단속운동이 머리 움직임 속도파형과 중복(covert)되 어 명확히 관찰되지 않았고, 억제 두부충동검사 결과 우측 수 
평으로 두부 회전 시 정상적 반보상적 단속운동이 관찰되는 반면, 좌측 수평으로 두부 회전 시 분산되며 진폭이 확연하 게 낮고, 지연된 비정상적 단속운동이 관찰되었다. 하지만 이 와 같이 명확한 반보상적 단속운동 지연이 아닌 정상적 반보 상적 단속운동이 병변 측에서 나타나는 환자도 있어 다른 전 정 기능 저하 환자군에 비하여 정확성과 민감성이 다소 떨어진 결과를 보여주었다.

\section{전정신경염}

전정신경염 환자의 경우, 현훈이 발생한 초기에 시행한 억제 두부충동검사 결과 반보상적 단속운동이 거의 관찰되지 않았 으나, 주관적으로 현훈을 적게 호소하게 된 회복기에 시행한 억제 두부충동검사 결과 반보상적 단속운동이 관찰되기 시 작하였다(Fig. 3).
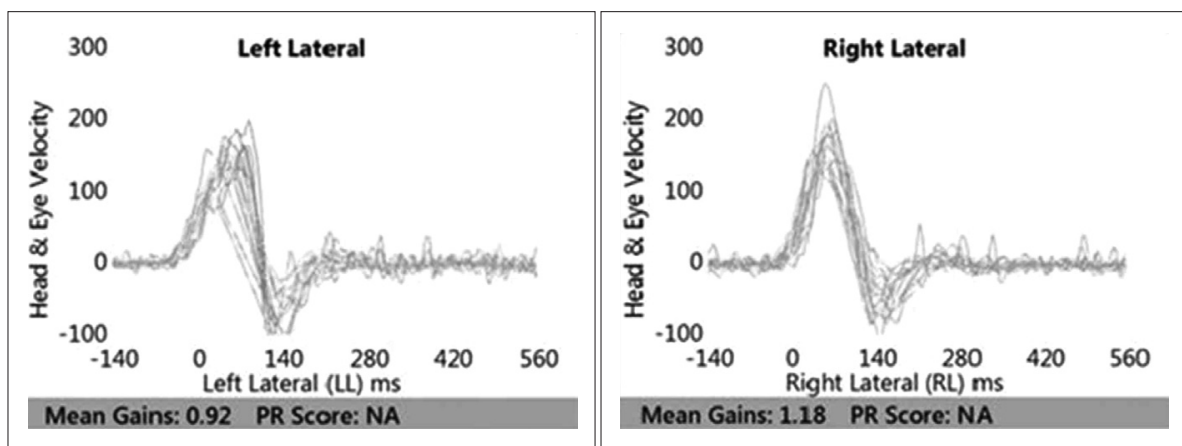

Mean Gains: 1.18 PR Score: NA

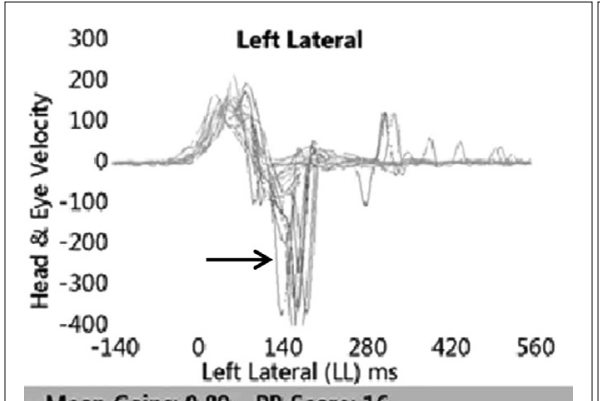

Mean Gains: 0.89 PR Score: 16

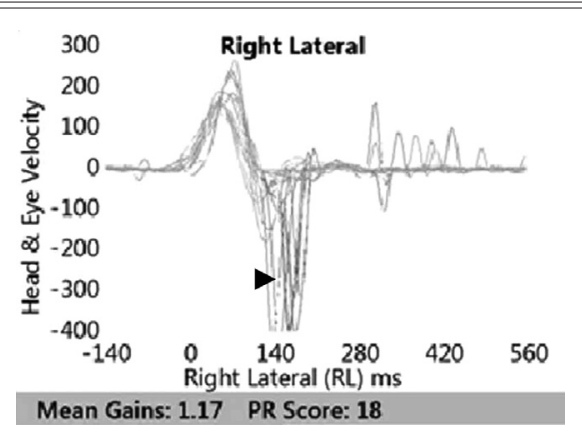

Mean Gains: 1.17 PR Score: 18
Fig. 1. Head and eye velocity recordings of VHIT (above) and SHIMP (below) of normal person. No saccade in cumulated recordings from repeated vHIT. Overt and anticompensatory saccadic eye movements in cumulated recordings from repeated SHIMP. Saccades (arrow) of SHIMP to left show VOR gain 0.89 , amplitude $319 \%$, latency $179 \mathrm{~ms}$. Saccades (arrowhead) of SHIMP to right show VOR gain 1.17 , amplitude $360 \%$, latency $161 \mathrm{~ms}$. VHIT: video head impulse test, SHIMP: suppression head impulse, VOR: vestibulo ocular reflex, PR: PR score (coefficient of variance), NA: non available.
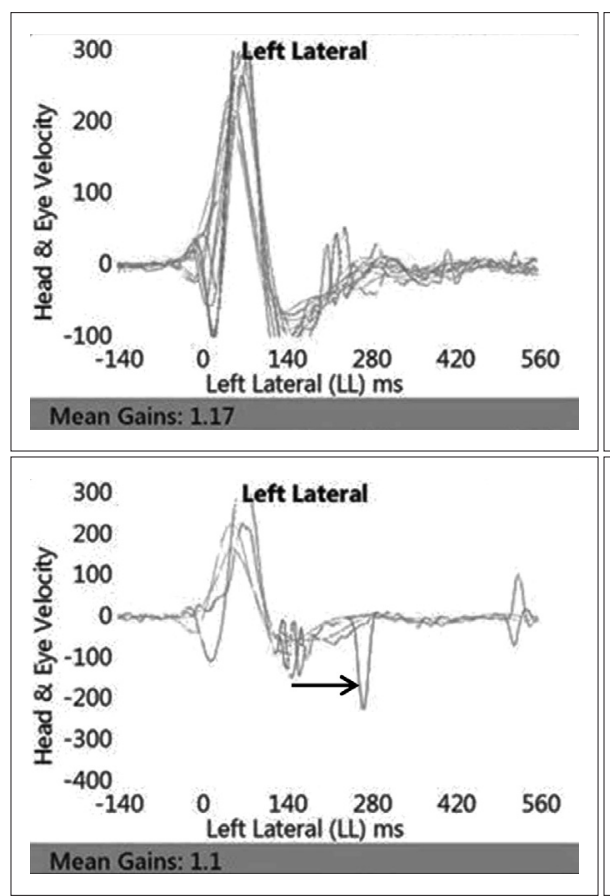

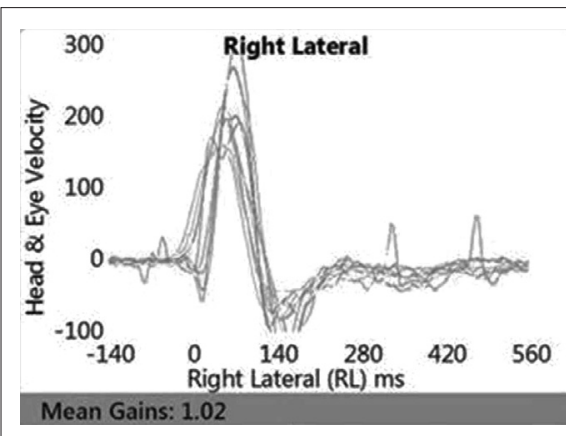

Mean Gains: 1.02

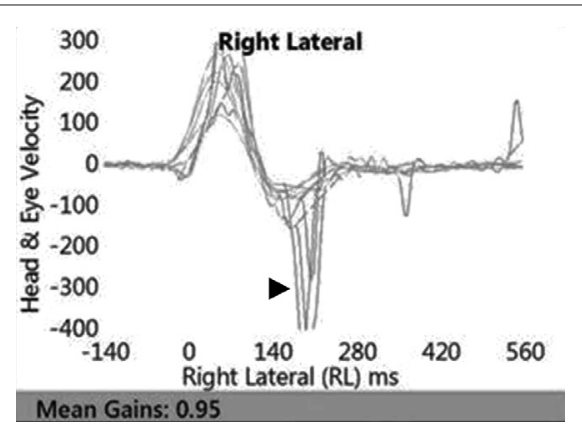

Fig. 2. Patterns of positive eye velocity recordings of VHIT (above) and SHIMP (below) in patient with left lateral canal benign paroxysmal positive vertigo. Unremarkable covert and compensatory saccadic eye movements in cumulated recordings from repeated vHIT-both normal and affected side. Overt and anticompensatory saccadic eye movements in cumulated recordings from repeated SHIMP. Remarkable left anticompensatory saccades (arrow: VOR gain 1.1 , amplitude $-56^{\circ} / \mathrm{s}$, latency $140 \mathrm{~ms}$ ) show lower amplitude and shorter latency from scattered pattern comparing with right anticompensatory saccades (arrowhead: VOR gain 0.95 , amplitude $-253^{\circ} / \mathrm{s}$, latency $238 \mathrm{~ms}$ ). vHIT: video head impulse test, SHIMP: suppression head impulse, VOR: vestibulo ocular reflex. 
메니에르병

메니에르병 환자군의 억제 두부충동검사 결과, 병변 측 방 향으로 고개를 수평 이동하였을 때 정상 측에 비하여 반보상 적 단속운동이 거의 관찰되지 않았다. 정상과 환 측의 단속 운동 차이는 기존 두부충동검사 결과 나타나는 보상적 단속 운동 차이보다 명확하게 나타났다(Fig. 4). 획득값은 억제 두 부충동검사 결과 상대적으로 작게 측정되었다.

\section{기타 전정 질환}

마지막으로 양측 전정 기능 저하 또는 결핵성 뇌수막염 환 자, 측두골 골절, 전정신경초종 환자의 억제 두부충동검사 결 과는 기존의 두부충동검사 결과와 마찬가지 혹은 보다 민감 하게 전정 기능 저하 정도를 평가하기 충분하였음을 확인할 수 있었다.

칼로리검사 결과 전체 반응값이 20보다 작은 양측 전정 기 능 저하 환자의 경우, 기존 두부충동검사에서는 좌측으로 두
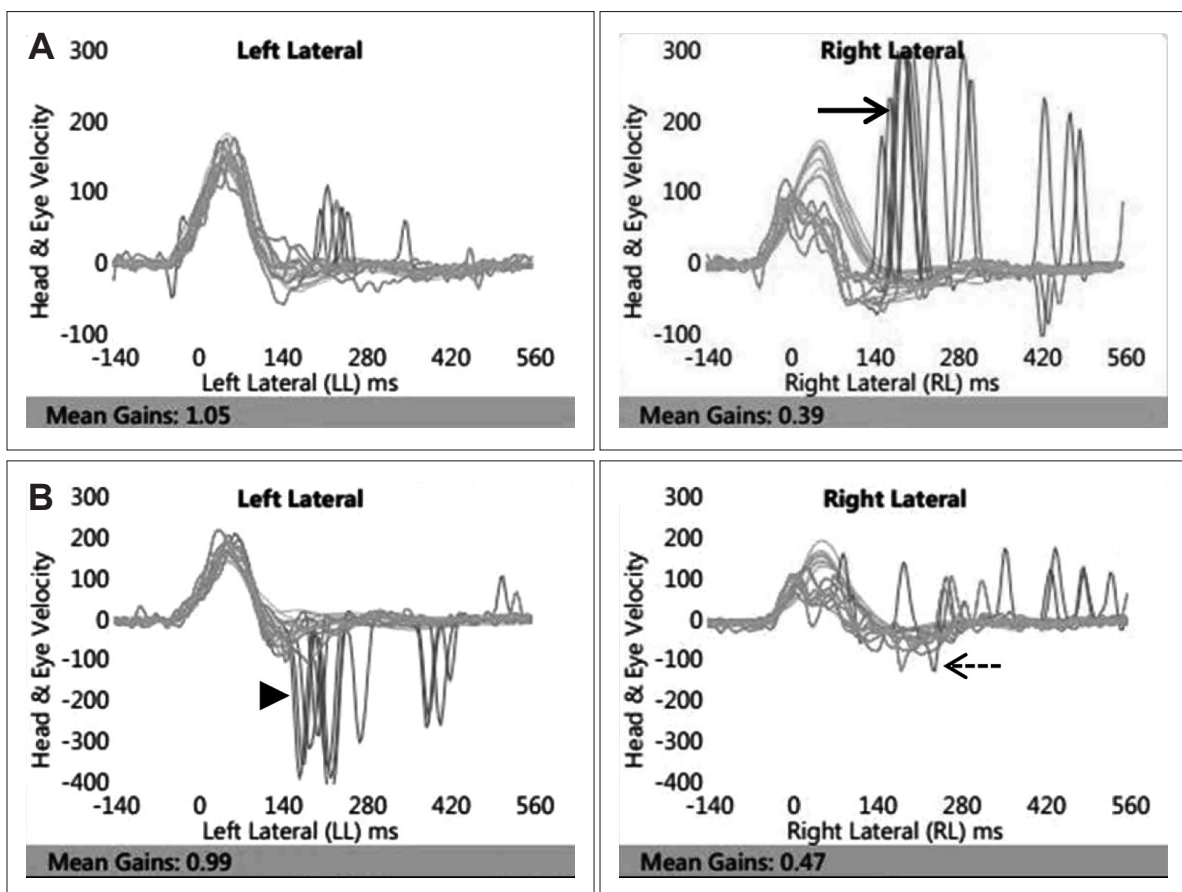

\section{Mean}
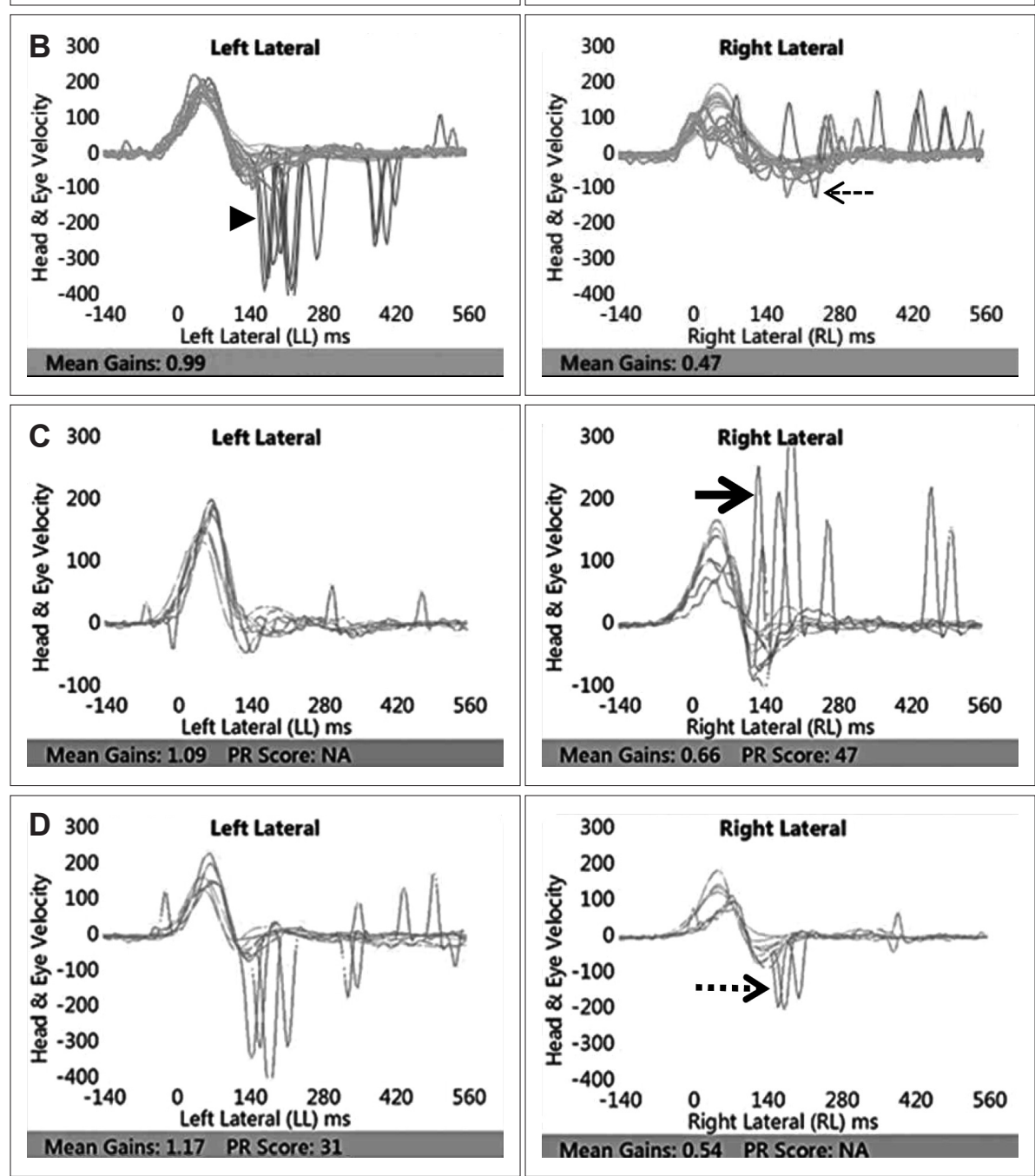

Fig. 3. Patterns of positive eye velocity recordings of VHIT (above) and SHIMP (below) in patient with right vestibular neuronitis-acute phase ( $A$ and $B$ ), recovered phase ( $C$ and D). In case of acute phase: remarkable compensatory saccadic eye movements (thin arrow: VOR gain 0.39 , amplitude $311 \%$ s, latency 188 $\mathrm{ms}$ ) in cumulated recordings from repeated VHIT. Small anticompensatory saccadic eye movements (thin dotted arrow: VOR gain 0.47 , amplitude $-61 \%$, latency $246 \mathrm{~ms}$ ) in cumulated recordings from repeated right SHIMP comparing with left anticompensatory saccades (normal side, arrowhead). In case of recovered phase: regressed covert and compensatory saccadic eye movements (thick arrow: VOR gain 0.66 , amplitude $241 \%$ s, latency $152 \mathrm{~ms}$ ) overlapped with head impulse in cumulated recordings from repeated right vHIT. Arising overt and anticompensatory saccadic eye movements (thick dotted arrow: VOR gain 0.54 , amplitude $-162 \%$ s, latency $184 \mathrm{~ms}$ ) in cumulated recordings from repeated right SHIMP. VHIT: video head impulse test, SHIMP: suppression head impulse, VOR: vestibulo ocular reflex, PR: PR score (coefficient of variance), NA: non available. 
부충동 시 보상성 단속운동이 미미하게 나타났으나, 우측으 로 두부충동 시 분명한 보상성 단속운동을 나타내는 차이를 보였다. 반면 억제 두부충동검사 결과 양측 두부충동에서 모 두 반보상성 단속운동이 거의 관찰되지 않거나, 분산되어 나 타났다(Fig. 5). 평균 획득값 또한 억제 두부충동검사에서 낮 게 측정되었다.

측두골 골절(Fig. 6), 전정신경초종(Fig. 7) 환자의 억제 두부
충동검사 결과 기존 두부충동검사와 마찬가지로 진폭이 작고 분산된 반보상성 단속운동이 관찰되어 대조군과 유의한 차 이를 보여주었다. 결핵성 뇌수막염 환자의 경우 4제 결핵 치 료요법 후 주관적 현훈이 호전되고, 시행한 억제 두부충동검 사 결과 회복 후에도 보상적 단속운동에 큰 차이가 없는 기존 두부충동검사 결과와 달리, 없었던 반보상성 단속운동이 나타 나기 시작하였다(Fig. 8).
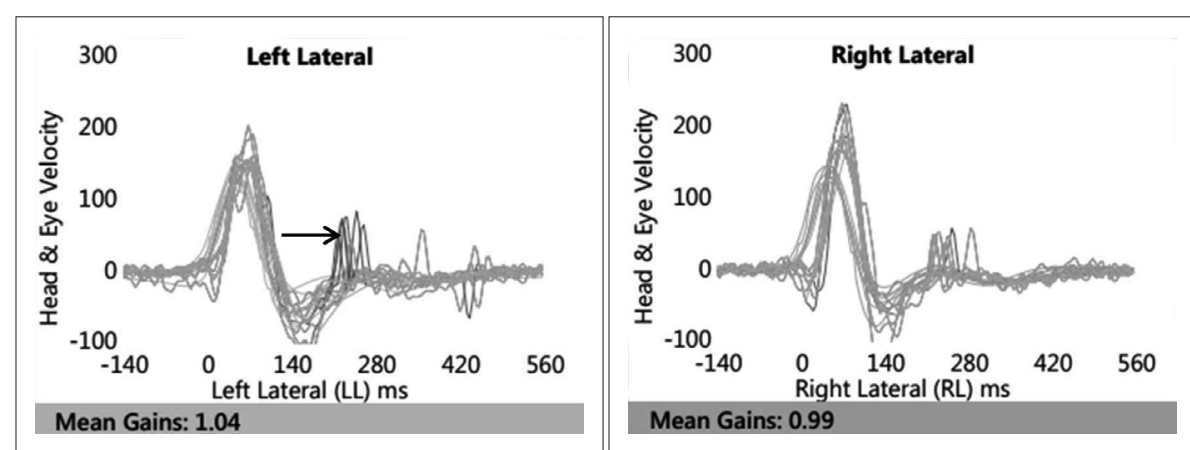

\section{Mean Gains: 0.99}

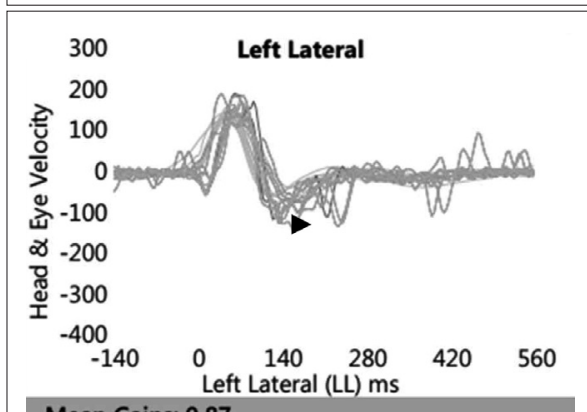

Mean Gains: 0.87

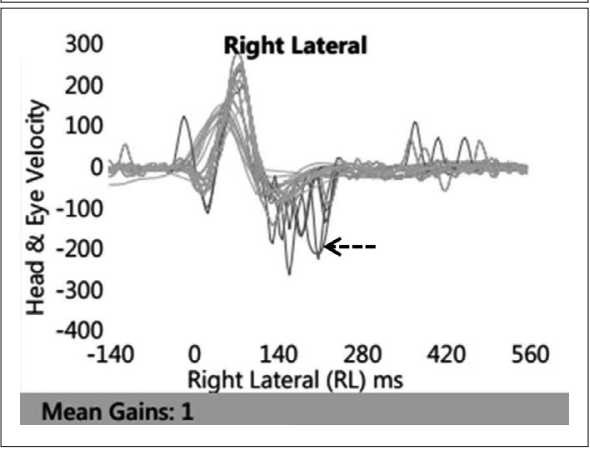

Mean Gains: 1
Fig. 4. Patterns of positive eye velocity recordings of VHIT (above) and SHIMP (below) in patient with left Meniere's disease. Unremarkable small compensatory saccadic eye movements (arrow: VOR gain 1.04, amplitude $88^{\circ} / \mathrm{s}$, latency $231 \mathrm{~ms}$ ) in cumulated recordings from repeated left VHIT. No anticompensatory saccadic eye movements (arrowhead) in cumulated recordings from repeated left SHIMP comparing with anticompensatory saccades (dotted arrow: VOR gain 1 , amplitude $-127^{\circ} \%$ $\mathrm{s}$, latency $168 \mathrm{~ms}$ ). vHIT: video head impulse test, SHIMP: suppression head impulse, VOR: vestibulo ocular reflex.
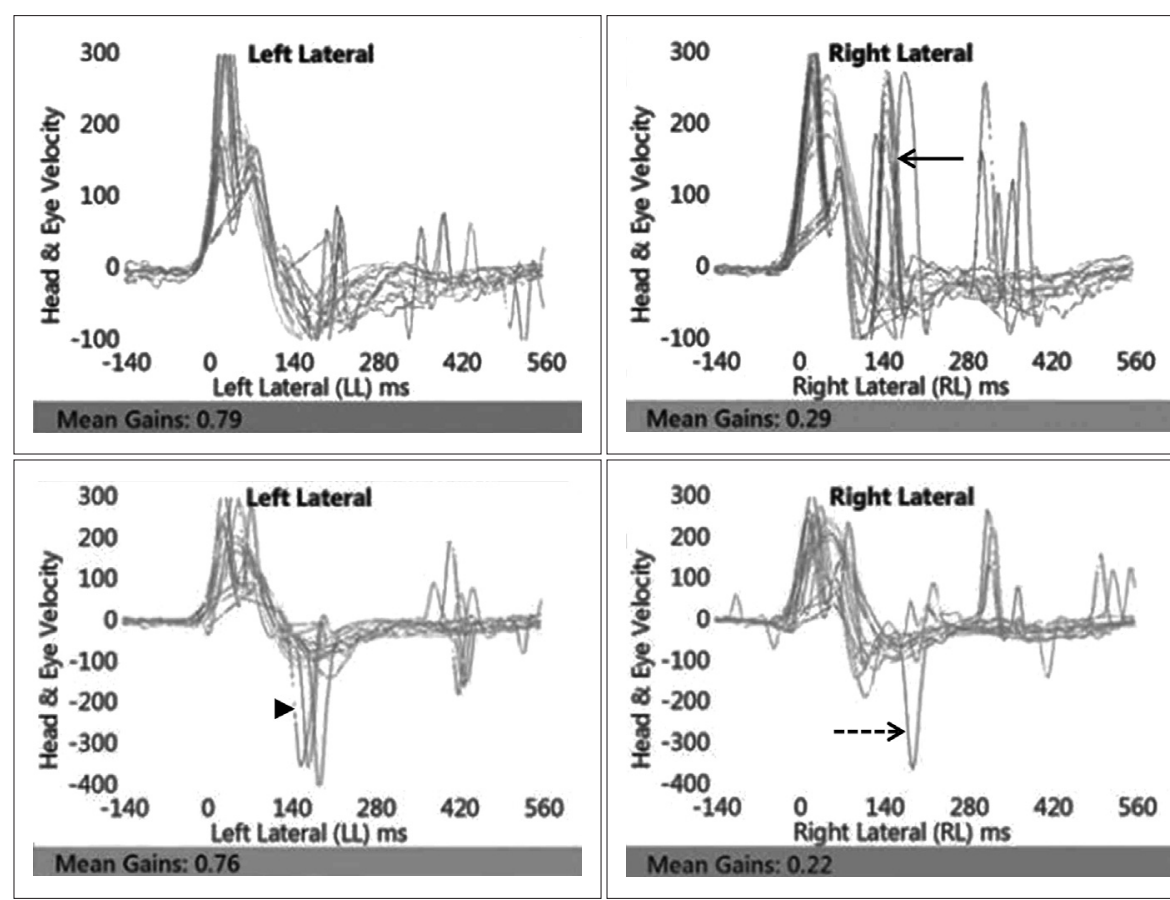

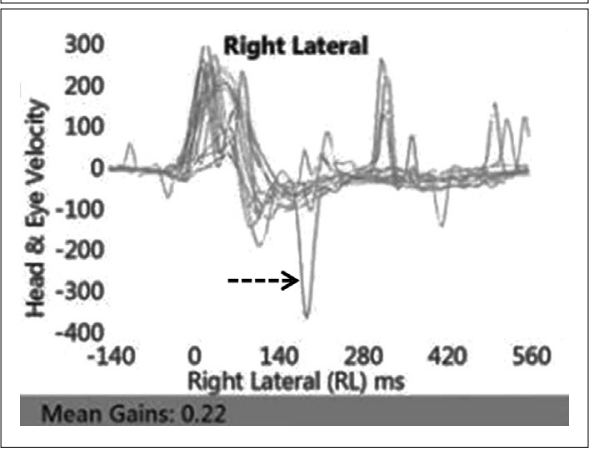

Fig. 5. Patterns of positive eye velocity recordings of VHIT (above) and SHIMP (below) in patient with bilateral vestibular function loss. Remarkable compensatory saccadic eye movements (arrow: VOR gain 0.29 , amplitude $279 \%$, latency $145 \mathrm{~ms}$ ) only in cumulated recordings from repeated right vHIT. Few or scattered anticompensatory saccadic eye movements in cumulated recordings from repeated left and right SHIMP (arrowhead: VOR gain 0.76 , amplitude $242 \%$ $\mathrm{s}$, latency $297 \mathrm{~ms}$, dotted arrow: VOR gain 0.22 , amplitude $306 \%$ s, latency $184 \mathrm{~ms}$ ). vHIT: video head impulse test, SHIMP: suppression head impulse, VOR: vestibulo ocular reflex. 
정상 대조군과 비교 시 저명한 획득값의 감소 및 지연값의 증 가를 보였던 질환군은 전정신경염, 측두골 골절, 결핵성 뇌수 막염, 양측 전정 기능 저하가 있는 환자군이었다. 메니에르병 에서는 획득값의 감소나 진폭의 감소는 저명하지 않으며 지연 값의 증가만 나타났다. 양성 돌발성 체위성 현훈에서는 결과 값에 이상이 없는 정상결과를 보인 환자군과 획득값은 정상 이나 지연값의 증가를 보인 환자군으로 나타났다(Table 1).

\section{고 찰}

전정 기능을 평가하는 객관적인 검사로는 칼로리검사, 전정유 발근 전위검사(vestibular evoked myogenic potential, vEMP), 전기와우도(electrocochleography, ECoG) 등이 오랜 기간 동 안 사용되어 왔다. 칼로리검사의 신뢰도는 높은 것으로 평가 되어 왔으나 일상생활에 나타나는 전정 자극에 대한 평가가
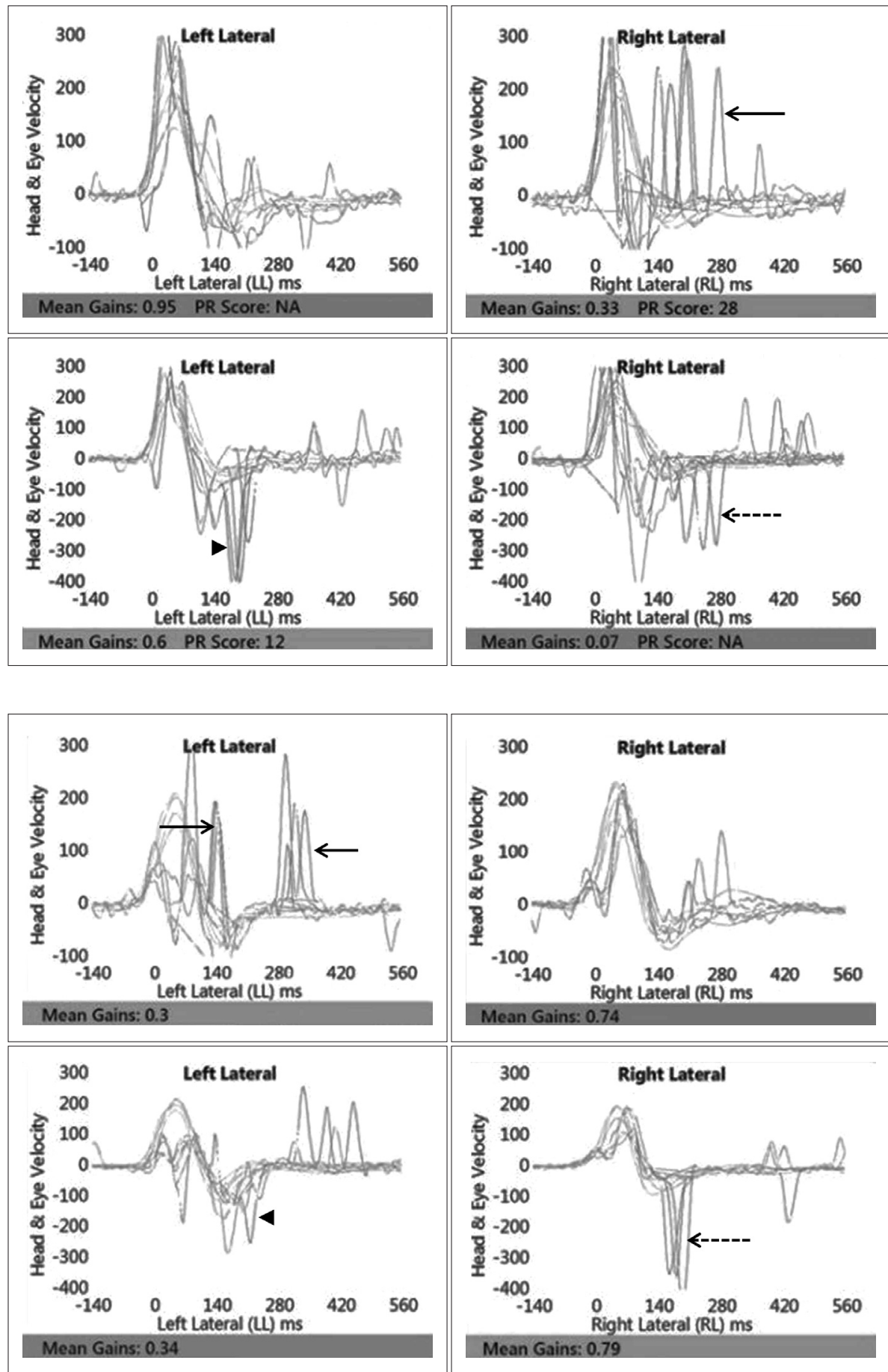

Fig. 6. Patterns of positive eye velocity recordings of VHIT (above) and SHIMP (below) in patient with temporal bone fracture. Scattered covert \& overt compensatory saccadic eye movements (arrow: VOR gain 0.33, amplitude $253 \%$, latency $177 \mathrm{~ms}$ ) in cumulated recordings from repeated right vHIT. Few and lower amplitude of anticompensatory saccadic right eye movements comparing with left anticompensatory saccades in $\mathrm{cu}-$ mulated recordings from repeated SHIMP (arrowhead: VOR gain 0.6, amplitude $337^{\circ} / \mathrm{s}$, latency $193 \mathrm{~ms}$ ) (dotted arrow: VOR gain 0.07, amplitude $272 \%$ s, latency $236 \mathrm{~ms}$ ). vHIT: video head impulse test, SHIMP: suppression head impulse, VOR: vestibulo ocular reflex, PR: PR score (coefficient of variance), NA: non available.
Fig. 7. Patterns of positive eye velocity recordings of VHIT (above) and SHIMP (below) in patient with left acoustic schwanomma. Scattered covert \& overt compensatory saccadic eye movements (arrow) in cumulated recordings from repeated left vHIT. Few, lower amplitude and shorter latency of left anticompensatory saccades (arrowhead: VOR gain 0.34 , amplitude $-166 \%$, latency $212 \mathrm{~ms}$ ) comparing with right anticompensatory saccades (dotted arrow: VOR gain 0.79 , amplitude $-313^{\circ} / \mathrm{s}$, latency $240 \mathrm{~ms}$ ) in cumulated recording from repeated SHIMP. VHIT: video head impulse test, SHIMP: suppression head impulse, VOR: vestibulo ocular reflex. 
아니기 때문에 이를 통해서 현훈을 느끼는 환자가 실생활에 서 주관적으로 느끼는 증상의 호전 정도, 즉 전정 재활 회복 정도를 예측하고 평가하기에 한계가 있었다.

두부충동검사는 전정 안반사를 확인할 수 있는 검사로, 1988년 고안된 이래 전정 기능검사 중 한 가지로 유용하게 사 용되고 있다. ${ }^{8)}$ 이는 머리 움직임에 대한 보상적인 눈의 단속 운동 유무로 전정 기능의 손실 유무를 파악하는 기전을 통해, 실제 생활에서 일어나는 자극을 통해 전정 상태를 평가할 수
있다. 전정 기능 손실이 있는 환자의 경우 전정 안반사(vestibulo-ocular reflex)의 소실로 인하여 머리가 움직일 때 타깃에 대한 시선 고정에 문제가 생겨, 타깃을 주시하지 못하게 되므 로 타깃으로 다시 눈이 움직여 따라잡는 보상적 단속운동이 지속적으로 일어날 것이며, 전정 기능에 문제가 없는 정상인 의 경우, 머리가 움직이더라도 눈은 타깃에 시선을 고정할 수 있어 보상적 단속운동이 거의 나타나지 않는 차이를 보인다. 비디오 두부충동검사는 이와 같은 원리를 이용하여 고정된
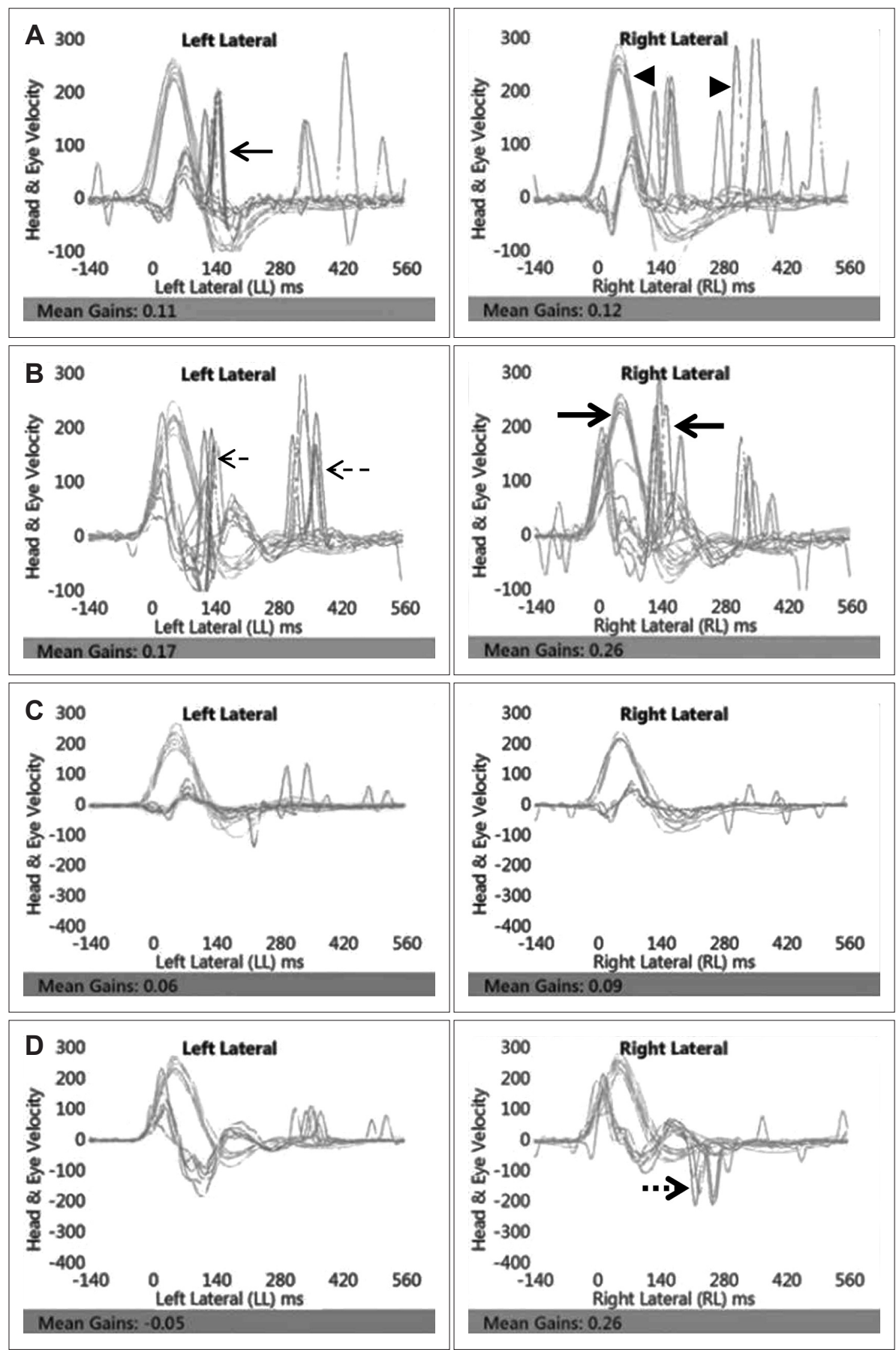

Fig. 8. Patterns of positive eye velocity recordings of VHIT (A and B) and SHIMP (C and D)-acute phase (above) and recovered phase (below) of patient with tuberculosis meningitis. In case of vHIT results: variable covert and overt compensatory saccadic eye movements (thin arrow: VOR gain 0.11 , amplitude $201 \%$ $\mathrm{s}$, latency $135 \mathrm{~ms}$ ) (arrowhead: VOR gain 0.12 , amplitude $256 \%$, latency $236 \mathrm{~ms}$ ) in cumulated recordings from repeated VHIT of acute phase. Remained covert \& overt compensatory saccades (thin dotted arrow: VOR gain 0.17 , amplitude $218 \%$ s, latency $274 \mathrm{~ms}$ ) (thick arrow: VOR gain 0.26 , amplitude $211 \%$, latency $178 \mathrm{~ms}$ ) in cumulated recordings from repeated VHIT of recovered phase. In case of SHIMP results: few or no anticompensatory saccadic both eye movements in acute phase (left VOR gain 0.06 , right VOR gain 0.09). Arising anticompensatory saccades (thick dotted arrow: VOR gain 0.26 , amplitude $-187^{\circ} / \mathrm{s}$, latency $231 \mathrm{~ms}$ ) in cumulated recordings from repeated right SHIMP in recovered phase. vHIT: video head impulse test, SHIMP: suppression head impulse, VOR: vestibulo ocular reflex. 
Suppression Head Impulse Test I Kang YJ, et al.

Table 1. VOR gain, amplitude, latency of VHIT, SHIMP result on normal and patients with vestibular function loss

\begin{tabular}{|c|c|c|c|c|}
\hline & \multicolumn{2}{|c|}{ VOR gain } & \multirow{2}{*}{$\begin{array}{c}\text { Amplitude }(\% / s) \\
\text { SHIMP }\end{array}$} & \multirow{2}{*}{$\begin{array}{c}\text { Latency (ms) } \\
\text { SHIMP }\end{array}$} \\
\hline & vHIT & SHIMP & & \\
\hline Normal $(n=1)$ & 1.13 & 0.88 & -323.00 & 165.5 \\
\hline Positive findings in patient with BPPV $(n=5)$ & 1.18 & 0.95 & -237.60 & 232.0 \\
\hline Normal findings in patient with BPPV $(n=3)$ & 1.11 & 0.81 & -303.67 & 233.0 \\
\hline Vestibular neuritis-acute phase $(n=3)$ & 0.62 & 0.78 & -194.00 & 250.0 \\
\hline Vestibular neuritis-resolved phase $(n=1)$ & 0.84 & 0.87 & -206.00 & 299.0 \\
\hline Meniere's disease $(n=8)$ & 1.07 & 1.01 & -238.63 & 242.0 \\
\hline Bilateral vestibular function loss $(n=1)$ & 0.54 & 0.49 & -274.00 & 240.5 \\
\hline TB fracture $(n=1)$ & 0.33 & 0.07 & -272.00 & 236.0 \\
\hline TB meningitis-acute phase $(n=1)$ & 0.12 & 0.08 & -119.00 & 220.0 \\
\hline TB meningitis-resolved phase $(n=1)$ & 0.22 & 0.11 & -187.00 & 231.0 \\
\hline Acoustic schwanomma $(n=1)$ & 0.3 & 0.34 & -166.00 & 212.0 \\
\hline
\end{tabular}

VOR: vestibulo ocular reflex, vHIT: video head impulse test, SHIMP: suppression head impulse, BPPV: benign paroxysmal positional vertigo, TB: temporal bone

타깃을 볼 때의 눈 움직임을 비디오로 분석하여 전정신경의 이상 여부에 대하여 알아보는 검사이다.)

한편 억제 두부충동검사에서 전정 기능 손실이 있는 환자 의 경우, 머리와 타깃에 대한 시선이 함께 움직여 전정 안반 사 작용 없이 시선 고정이 유지되므로 단속운동이 나타나지 않는다. 반면, 전정 기능에 문제가 없는 정상인의 경우 머리가 움직인 뒤 전정 안반사 작용이 나타나므로 시선이 타깃을 주 시하기 위한 반보상적 단속운동이 역으로 일어나는 원리를 이용한 검사이다. 2.9$)$

주요 사용되는 검사상의 지표는 전정 안반사의 획득값(gain), 지연값(latency)과 진폭값(amplitude)이다. 전정 기능이 정상 인의 경우 기존 두부충동검사 결과 획득값은 평균 1.0 으로 측정되는 데 비해 억제 두부충동검사에서의 획득값은 두부 충동검사에 비해 약 0.06 정도 낮게 측정된다. 이는 억제 두 부충동검사 시 머리 움직임과 함께 움직이는 눈 앞의 타깃을 주시하도록 하는 검사의 조건 자체가 전정 안반사의 획득값 을 억제하는 효과가 있기 때문이다. 기존 논문에서 밝혀진 바 와 같이 ${ }^{1)}$ 본 연구에서 전정 안반사의 획득값은 억제 두부충동 검사에서 기존 두부충동검사보다 0.05 0.2 정도 낮게 측정됨 을 확인하였다.

지연값은 강한 단속운동이 관찰되는 시점을 의미하는데, 정상인의 경우 $185 \mathrm{~ms} \pm 20$ standard deviation 정도의 평균 값을 보인다. ${ }^{1)}$ 두부충동검사 시 머리를 회전시키는 자극 방향 으로 따라가는 눈의 움직임이 두부충동 속도보다 느려지는 순간 눈은 타깃을 놓치게 된다. 이때 타깃을 따라잡기 위한 전정 안반사가 일어나는 작용 시간 동안, 즉 머리 회전 자극 이 멈춘 직후인 약 160 200 ms 전후에서 강한 반보상적 단 속운동이 관찰되고 이 시점이 지연값이다. ${ }^{7)}$ 평균 지연값보다 빠르게 혹은 지연되어 단속운동이 나타나는 경우 전정 기능에
이상이 있음을 의미한다.

이와 같은 원리를 이용하는 억제 두부충동검사의 효용성 은 첫째, 억제 두부충동검사는 고전적인 두부충동검사에서 머리와 눈의 움직임의 속도 그래프가 중복되어 나타나 명확 하게 구분할 수 없었던 보상적 단속운동(covert)에 비하여, 두부충동의 속도 그래프보다 지연적 및 반보상적 단속운동 이 명확하게 나타나기 때문에 획득값, 지연값, 진폭값을 더 정확하게 계산할 수 있다는 장점이 있다. 이는 전정신경 기능 저하 여부를 보다 분명하게 판단하는 데 도움을 준다. 구체적 으로 가장 민감도가 높은 것으로 보여진 전정신경염의 경우 대조군에 비하여 증상 발현 초기에 억제 두부충동검사의 반 보상적 단속운동이 관찰되지 않은 점을 바탕으로 칼로리검 사와 고전적 두부충동검사와 함께 유용한 선별검사로 이용 할 수 있는 가능성을 확인할 수 있었다. 양성 발작성 체위성 현훈 환자의 경우, 전정신경염에 비하여 반보상적 단속운동 이 일정하게 나타나지 않는 경우도 드물게 관찰되었고 이는 이석의 위치나 양에 따라 억제 두부충동검사 결과의 양성값 이 다르게 나올 가능성에 기인함으로 생각되었다. 하지만 이 러한 가설을 뒷받침할 수 있는 변수에 대한 추가적인 연구가 필요할 것으로 보인다. 메니에르병의 경우, 대부분 다른 전정 기능 저하 질환보다 상대적으로 긴 이환 기간 동안 증상 악화 및 호전을 반복하였기 때문에 진폭값과 지연값이 다른 질환 군의 결과보다 저하되어 나타났을 가능성이 있으며, $\mathrm{ECoG}$ 와 VEMP 결과와 함께 결과값을 분석 시 편측 전정 기능 저하 의 방향과 정도를 명확하게 판단할 수 있을 것으로 생각되었 다. 둘째, 고전적 두부충동검사가 고정된 목표물을 계속 주 시하게 함으로써 병변 방향으로의 두부 회전운동 시 뒤따르 는 안구 보상적 단속운동의 정도를 통해 병변의 진단과 기능 소실의 정도를 파악하고 진단하는 데 도움을 주는 반면, 억제 
두부충동검사는 두부 움직임이 흔히 발생하는 실생활에서 두부의 움직임과 이에 뒤따르는 같은 방향으로의 안구의 반 보상적 움직임을 파악하는 것으로 실생활에서 환자가 느끼 는 전정 기능 저하 평가에 보다 유용하다고 할 수 있을 것이 다. 앞서 살펴본 증례 중 특히 양성 발작성 체위성 현훈, 메니 에르병, 양측 전정 기능 저하, 결핵성 뇌수막염의 경우 억제 두부충동검사에서 보다 명확한 양성 결과가 확인되었다. 셋 째, 급성기 및 회복기의 억제 두부충동검사 값의 변화를 통 해 환자의 전정 기능의 조기 회복을 확인할 수 있으며 특히 칼로리검사상 전정 기능의 심한 저하가 진단된 환자에서도 전정병증의 단계가 구체적으로 급성기인지 회복기인지를 예 측하는 데 도움을 줄 수 있다. 즉 잔존 전정 기능을 평가하 여 노인 환자 등 만성 현훈 환자의 실제적인 부적응 정도나 전정 기능의 급성 저하 이후의 전정 재활 정도 평가에 큰 도 움이 될 것이다. 구체적으로 앞서 살펴본 환자군 중에서, 급 성기 및 회복기에서 모두 분명한 보상성 단속운동을 보인 기 존 두부충동검사와 달리 억제 두부충동검사 결과가 보다 효 율적으로 결핵성 뇌수막염 환자의 전정 안반사 회복을 평가 하고 나아가 현훈 환자의 추적 관찰용 검사로 용이하게 사용 될 수 있는 가능성을 확인할 수 있었다. 아울러 모든 경우에 서 억제 두부충동검사의 획득값이 낮게 측정되었고 특히 결 핵성 뇌수막염 환자의 경우 급성기에는 상대적으로 더 낮게 측정되어 정상값보다 분명한 차이를 보였으며, 회복기에서의 획득값 증가 정도는 기존 두부충동검사 결과보다 분명하게 나타났다.

검사 시 주의점으로는 검사 방법의 정확도를 높이기 위해 전정 안반사를 확인하기 충분할 정도의 빠른 스냅으로 머리 회전 자극(최대 속도 150 250\% 정도)을 주어야 하며, 적합한 회전 각도는 $18 \sim 20^{\circ}$ 로 보고된 바 있다. ${ }^{1)}$ 또한 지나치게 빠른 스냅으로 인한 역회전 혹은 바운스(bounce)가 없어야 한다. 그렇지 않은 경우 결과값에 인위적 영향(artifact)이 발생할 수 있다. ${ }^{7)}$ 이에 검사자의 숙련도와 정량화에 보다 중점을 두어 추가적인 연구를 시행하고자 한다.

피험자의 측면에서는 눈이 작거나 눈썹에 문신 혹은 긴 속
눈썹이 있는 경우 비디오에서 눈의 움직임을 읽기 어려우므로 눈을 크게 뜨고 방해가 될 수 있는 상태를 배제시킨 후 검사 에 임하여야 한다. 따라서 노인이나 협조가 되지 않는 환자, 눈 의 구조적 이상이 있는 환자의 경우 검사의 정확도가 떨어질 수 있음에 유의해야 한다.

한편 본 연구에서 대상 환자군 수가 적어(총 $n=24$, 각 질환 별 $n=1 \sim 8)$ 일반화하기에 부족한 점이 있을 수 있으나, 질환별 로 억제 두부충동검사가 갖는 유용성을 확인하기 위한 선행 연구로서 그 의미를 두고자 하였기에 본 연구를 기반으로 더 많은 증례 분석을 통해 추가적인 연구를 시행하고자 한다. 아울러 이환 기간 내 시행한 추적 두부충동검사가 3 개월 내 시행한 검사 최대 1 회로, 보다 장기간 추적검사를 시행한다 면 더욱 신뢰도 높은 결과를 얻을 수 있을 것이라 사료된다.

\section{REFERENCES}

1) MacDougall HG, McGarvie LA, Halmagyi GM, Rogers SJ, Manzari L, Burgess AM, et al. A new saccadic indicator of peripheral vestibular function based on the video head impulse test. Neurology 2016;87(4):410-8.

2) Macdougall HG, McGarvie LA, Halmagyi GM, Curthoys IS, Weber KP. The video Head Impulse Test (vHIT) detects vertical semicircular canal dysfunction. PLoS One 2013;8(4):e61488.

3) MacDougall HG, Weber KP, McGarvie LA, Halmagyi GM, Curthoys IS. The video head impulse test: diagnostic accuracy in peripheral vestibulopathy. Neurology 2009;73(14):1134-41.

4) Weber KP, Aw ST, Todd MJ, McGarvie LA, Curthoys IS, Halmagyi GM. Head impulse test in unilateral vestibular loss: vestibulo-ocular reflex and catch-up saccades. Neurology 2008;70(6):454-63.

5) Weber KP, Aw ST, Todd MJ, McGarvie LA, Curthoys IS, Halmagyi GM. Horizontal head impulse test detects gentamicin vestibulotoxicity. Neurology 2009;72(16):1417-24.

6) Lehnen N, Glasauer S, Jahn K, Weber KP. Head impulses in complete bilateral vestibular loss: catch-up saccades require visual input. Neurology 2013;81(7):688-90.

7) Mantokoudis G, Saber Tehrani AS, Kattah JC, Eibenberger K, Guede CI, Zee DS, et al. Quantifying the vestibulo-ocular reflex with videooculography: nature and frequency of artifacts. Audiol Neurootol 2015; 20(1):39-50.

8) Halmagyi GM, Curthoys IS. A clinical sign of canal paresis. Arch Neurol 1988;45(7):737-9.

9) Shen Q, Magnani C, Sterkers O, Lamas G, Vidal PP, Sadoun J, et al. Saccadic velocity in the new suppression head impulse test: a new indicator of horizontal vestibular canal paresis and of vestibular compensation. Front Neurol 2016;7:160. 